\title{
Ventriculoiliac shunt: a cadaveric feasibility study
}

\author{
R. Shane Tubbs, MS, PA-C, PhD, ${ }^{1,2}$ Isaiah Tubbs, ${ }^{1}$ Marios Loukas, MD, PhD, ${ }^{2}$ \\ and Aaron A. Cohen-Gadol, MD, MSc ${ }^{3}$
}

\begin{abstract}
${ }^{1}$ Pediatric Neurosurgery, Children's Hospital, Birmingham, Alabama; 2Department of Anatomical Sciences, St. Georges University, St. Georges, Grenada; and ${ }^{3}$ Goodman Campbell Brain and Spine, Indiana University Department of Neurological Surgery, Indianapolis, Indiana
\end{abstract}

OBJECT Additional distal sites for placement of CSF diversionary shunts may be necessary in some patients. The present study aimed to investigate the marrow space of the ilium as a potential receptacle for CSF in patients with hydrocephalus.

METHODS Cannulation of the marrow space of the ilium was performed in 5 fresh human cadavers less than 4 hours from time of death. Tap water was infused via a metal trocar for approximately 60 minutes.

RESULTS A total of $30 \mathrm{~L}$ of water was easily injected into all cadaveric specimens without overflow from the infusion site or noticeable edema of the body. Upon inspection of the thoracic and abdominal cavities, no fluid accumulation was identified, ensuring that all infused fluid had gone into the vascular system.

CONCLUSIONS Based on this cadaveric study, the ilium appears to be an ideal location for placement of the distal end of a CSF diversionary shunt when other anatomical receptacles are not an option. In vivo human studies are now required to verify these findings.

http://thejns.org/doi/abs/10.3171/2014.10.PEDS14252

KEY WORDS hydrocephalus; shunts; complications; cerebrospinal fluid

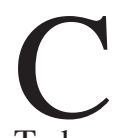

EREBROSPINAL fluid diversionary methods have many potential complications (e.g., infection, ob(the distal site) Today, the most common site of implantation is the peritoneum. Other commonly used sites include the pleural cavity and the heart. When these sites cannot be used because of malabsorption or congenital or acquired pathology of these cavities, the surgeon must investigate less frequently used anatomical receptacles (e.g., the gall bladder). One site that, to our knowledge, has not been explored as a potential receptacle for CSF is the marrow space of the ilium. The present study was performed to investigate the feasibility of infusing large amounts of fluid into the ilium. This model will assess the capability of the ilium as a receptacle for CSF diversion.

\section{Methods}

We used 5 fresh human cadavers ( 2 male and 3 female) who were less than 4 hours from the time of death and aged 56-87 years (mean 79 years) at death. None of the cadavers had previously undergone any prior surgical intervention near the ilium. With each cadaver supine, we made a small 2-cm skin incision along the anterior aspect of the iliac crest. To access the cancellous bone, we pushed an 8- to 10-mm-diameter, sharp-tipped, metal trocar into the iliac crest parallel to its anterior and posterior walls and to a depth of approximately $3-4 \mathrm{~cm}$. A fluid injector (Duotronic Injector, Edwards Equipment Co.) was used to introduce fluid into the defect (marrow cavity) through a metal trocar (1-cm diameter), and bone wax was used to ensure a good seal between the trocar and the round defect made into the ilium. Tap water was infused at 3-10 psi (mean 5 psi) over 40-60 minutes (mean 52 minutes). Because of the nonfunctioning circulatory system of the cadavers, the injection time was limited to 1 hour. To observe for distal fluid accumulation within the bony intramedullary systems of the body, we made a small hole into the left or right tibia to ensure intramedullary egress of infused fluid. Finally, the cranial, thoracic, and abdominal cavities were opened and examined for fluid loss or accumulation (Fig. 1). 


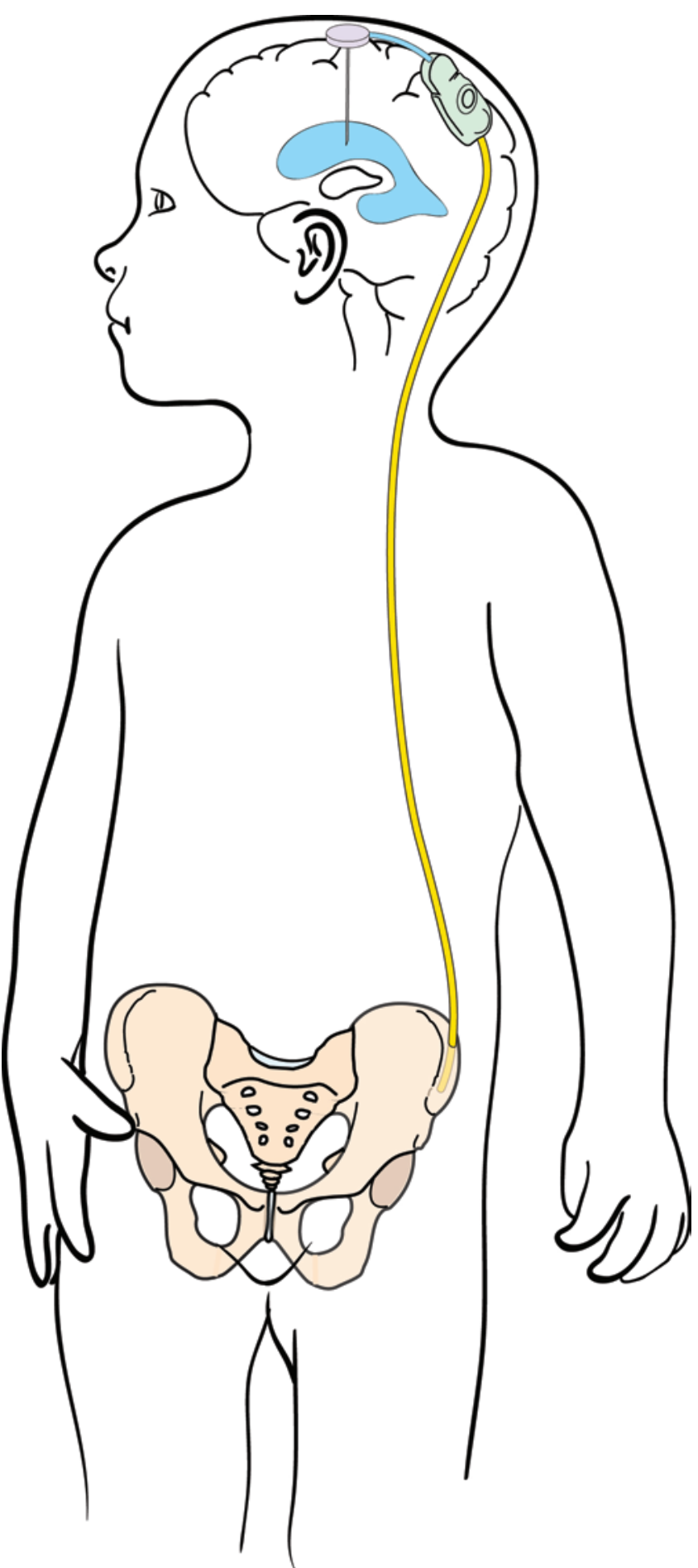

FIG. 1. Schematic drawing illustrating the proposed placement of a ventriculoiliac shunt. Copyright R. Shane Tubbs. Published with permission. Figure is available in color online only.

\section{Results}

We were able to use the trocar to enter the intraosseous compartment of the ilium in all cadaveric specimens without difficulty. The trocar was used to disrupt the fine trabeculae within this compartment. We injected a total of $30 \mathrm{~L}$ of fluid into all specimens without overflow from the infusion site or noticeable edema of the torso. At approximately 10 minutes after infusion, egress of water was noted from the tibia, which represents filling of the vascular and intramedullary spaces of the body. Upon direct inspection of the cranial, thoracic, and abdominal cavities, no fluid accumulation was identified, confirming that all infused fluid had gone into the vascular system. In all cadavers, we inserted the distal 6-cm-long shunt tubing (Medtronic) into the marrow cavity of the ilium.

\section{Discussion}

Different routes and alternate repositories for CSF diversion have been described. Other than the more commonly used peritoneal, pleural, and atrial cavities, other examples include the Fallopian tubes, gall bladder, and thoracic and parotid ducts. Proposed intraosseous locations for CSF diversion have included the mastoid process and diploic spaces. ${ }^{6,8}$ Intradiploic CSF fistulas are further evidence for the ability of the intradiploic space to absorb CSF. ${ }^{1}$

Intraosseous infusion into the tibia for emergent fluid resuscitation is well known. ${ }^{3}$ A lesser-known site for this type of fluid delivery is the sternum. This site has been found to be easier to penetrate compared with the tibial plateau or distal femur and accommodates the administration of emergency drugs and fluids, including crystalloid solutions, albumin, and blood products. ${ }^{4}$ One report found no difference between sternal intraosseous infusion and peripheral vascular access in adults in terms of blood pressure response and there were no complications. ${ }^{2}$ We have reported our findings that the manubrium of the sternum might be considered as a site to implant distal CSF shunts. ${ }^{7}$ This earlier animal study also demonstrated that long-term intraosseous infusion was well tolerated and without complications.

Our study describes the ability of the marrow spaces of the postmortem human ilium to accept at least $30 \mathrm{~L}$ of fluid during a 1-hour time period. Marrow spaces have been found to tolerate flow rates of up to $80 \mathrm{ml} / \mathrm{min}$ for gravity drip and more than $150 \mathrm{ml} / \mathrm{min}$ from a syringe bolus. ${ }^{5}$ Since CSF is produced at approximately $0.33 \mathrm{ml} / \mathrm{min}$, this capacity for fluid ingress would seem more than adequate to handle such additional fluid load in patients with hydrocephalus. The pathway from the medullary space of the ilium would be first to the intraosseous veins of this bone, drainage into medullary veins leaving the bone, entry into the inferior vena cava, and then to the heart.

For implantation of a ventriculoiliac shunt system, we would foresee placement of a standard ventricular catheter, with the distal tubing passed subcutaneously to the region of the lower lateral abdominal wall after the catheter is connected to a valve. The previously described devices that insert the distal catheter into the diploic space may also be used to maintain the catheter within the bone marrow of the ilium. ${ }^{3,6}$

Osteomyelitis of the ilium would be a contraindication to our technique. ${ }^{4}$ Potential complications would also include osteomyelitis. Due to the vicinity of the ilium to the abdomen, the former may be used as a receptacle for the distal shunt catheter during shunt revision, if the abdomen 
is no longer considered the appropriate absorption destination for the shunt system.

\section{Conclusions}

Our study supports the use of the ilium as the distal receptacle and absorption site for CSF diversion. In vivo human studies are now necessary to confirm the safety and indications for ventriculoiliac shunts.

\section{References}

1. Chávez-Negrete A, Majluf Cruz S, Frati Munari A, Perches A, Argüero R: Treatment of hemorrhagic shock with intraosseous or intravenous infusion of hypertonic saline dextran solution. Eur Surg Res 23:123-129, 1991

2. D'Almeida AC, King RB: Intradiploic cerebrospinal fluid fistula. Report of two cases. J Neurosurg 54:84-88, 1981

3. Jun H, Haruyama AZ, Chang KS, Yamamoto LG: Comparison of a new screw-tipped intraosseous needle versus a standard bone marrow aspiration needle for infusion. Am J Emerg Med 18:135-139, 2000

4. Koschel MJ: Sternal intraosseous infusions: emergency vascular access in adults. Am J Nurs 105:66-68, 2005

5. Macnab A, Christenson J, Findlay J, Horwood B, Johnson D, Jones L, et al: A new system for sternal intraosseous infusion in adults. Prehosp Emerg Care 4:173-177, 2000
6. Pugh JA, Tyler J, Churchill TA, Fox RJ, Aronyk KE: Intraosseous infusion into the skull: potential application for the management of hydrocephalus. J Neurosurg 106 (2 Suppl):120-125, 2007

7. Tubbs RS, Bauer D, Chambers MR, Loukas M, Shoja MM, Cohen-Gadol AA: A novel method for cerebrospinal fluid diversion: a cadaveric and animal study. Neurosurgery 68:491-495, 2011

8. Vinas FJ: [Ventriculomastoid shunt: its indications.] Rev Fac Cienc Med Cordoba 22:159-162, 1964 (Span)

\section{Author Contributions}

Conception and design: Cohen-Gadol, RS Tubbs, Loukas. Acquisition of data: RS Tubbs, I Tubbs, Loukas. Analysis and interpretation of data: all authors. Drafting the article: all authors. Critically revising the article: all authors. Reviewed submitted version of manuscript: all authors. Approved the final version of the manuscript on behalf of all authors: Cohen-Gadol. Study supervision: RS Tubbs.

\section{Correspondence}

Aaron A. Cohen-Gadol, Goodman Campbell Brain and Spine, Indiana University Department of Neurological Surgery, 355 W. 16th St., Ste. 5100, Indianapolis, IN 46202-1259. email: acohenmd@gmail.com. 